\title{
La Linguistique de Claudel. Histoire, style, savoirs, sous la direction d'Emmanuelle Kaës, Didier Alexandre
}

\section{Simonetta Valenti}

\section{(2) OpenEdition}

1 Journals

\section{Edizione digitale}

URL: http://journals.openedition.org/studifrancesi/593

DOI: 10.4000/studifrancesi.593

ISSN: 2421-5856

\section{Editore}

Rosenberg \& Sellier

\section{Edizione cartacea}

Data di pubblicazione: 1 aprile 2015

Paginazione: 189-190

ISSN: 0039-2944

\section{Notizia bibliografica digitale}

Simonetta Valenti, «La Linguistique de Claudel. Histoire, style, savoirs, sous la direction d'Emmanuelle Kaës, Didier Alexandre », Studi Francesi [Online], 175 (LIX | I) | 2015, online dal 01 avril 2015, consultato il 18 septembre 2020. URL : http://journals.openedition.org/studifrancesi/593 ; DOI : https://doi.org/ 10.4000/studifrancesi.593

Questo documento è stato generato automaticamente il 18 settembre 2020.

\section{(c)}

Studi Francesi è distribuita con Licenza Creative Commons Attribuzione - Non commerciale - Non opere derivate 4.0 Internazionale. 


\title{
La Linguistique de Claudel. Histoire, style, savoirs, sous la direction d'Emmanuelle Kaës, Didier Alexandre
}

\author{
Simonetta Valenti
}

\section{NOTIZIA}

La Linguistique de Claudel. Histoire, style, savoirs, sous la direction d'Emmanuelle KAËs, Didier ALEXANDRE, Paris, Classiques Garnier, 2014 («Rencontres», 71), pp. 212.

1 Il presente volume raccoglie una serie di saggi, tesi ad esplorare il rapporto di Paul Claudel con la scienza linguistica del suo tempo. I diversi contributi presentati mettono in luce come, per l'autore de Le Soulier de satin, la riflessione linguistica nasca sempre dal dato concreto, ovvero dall'osservazione dei fenomeni in atto nel complesso tessuto del testo, che Claudel manipola, al fine di ottenere uno stile poetico originale, ove $\mathrm{i}$ molteplici registri linguistici si fondono in una singolare mescolanza.

2 Nel corposo articolo di apertura (pp. 5-62), Didier ALEXANDRE illustra i principali presupposti teorici su cui si fonda il cratilismo claudeliano, che trova la sua massima espressione nella creazione dell'ideogramma, nato alla confluenza del pensiero cinese e della concezione tomistica del segno linguistico.

3 Nel contributo di Christelle BARBIER (pp. 63-90), si prendono poi in considerazione le diverse posizioni della critica rispetto al capolavoro claudeliano, mostrando come Claudel sia riuscito a integrare nel Soulier de satin la dimensione critica, indicando il giusto atteggiamento interpretativo da tenere nei confronti del suo dramma testamentario, all'interno del quale la diversità linguistica, etnica, culturale è sempre considerata elemento irrinunciabile di arricchimento. 
4 Emmanuelle KAËs, dal canto suo, studia la concezione claudeliana della grammatica comparata (pp. 91-117), mettendo in luce come lo scrittore novecentesco abbia subìto l'influenza di Mallarmé, che Claudel rivisita tuttavia in chiave enunciativa e pragmatica. In particolare, l'autore degli Idéogrammes occidentaux attribuisce una netta predominanza al significante grafico della parola, ovvero alla lettera, aprendo la strada a un processo di «idéogrammatisation» che si allarga ad abbracciare tutto il linguaggio.

5 Carla VAN DEN BERGHE analizza nel suo articolo (pp. 119-148) la nozione del versetto claudeliano, facendo emergere le principali linee evolutive che dal verso libero di matrice simbolista, presente soprattutto nei drammi giovanili, conducono progressivamente Claudel alla sperimentazione e alla definizione del verso della maturità, caratterizzato da un parallelismo interno di tipo binario.

6 Pascal LÉCROART (pp. 149-173) esplora a sua volta la definizione claudeliana del verso, inteso come «ïambe fondamental», mettendo in risalto quanto, al di là di talune oscillazioni terminologiche, esso si identifichi per Claudel con un equilibrio qualitativo interno, ovvero come un accordo sapientemente modulato tra le diverse sonorità vocaliche che contraddistinguono i due momenti in cui esso è suddiviso.

7 Christelle REGGIANI (pp. 175-185) passa in rassegna nel suo contributo i diversi arcaismi presenti nelle opere di Claudel, indicando i vari stati di lingua che da essi si possono evincere, dal latino al francese classico, passando per l'antico francese di fantasia de L'Annonce faite à Marie.

8 Infine, analizzando le «phrases clivées» e "demi-clivées» che contraddistingono il dialogo teatrale ne Le Soulier de satin (pp. 187-203), Frédéric CALAS ne chiarisce il significato, dimostrando che esse permettono di ricostruire quello che il critico definisce un «intradiscours catholique», volto alla ricerca e all'affermazione delle leggi nascoste che governano l'universo umano e naturale, e che il poeta identifica infine in Dio stesso. 